\title{
Criteria Analysis of Food Safety using the Analytic Hierarchy Process (AHP) - A Case study of Thailand's Fresh Markets
}

\author{
Chewaphorn Chaiyaphan ${ }^{1 *}$, Kasin Ransikarbum ${ }^{1 *}$ \\ ${ }^{1}$ Department of Industrial Engineering, Ubonratchathani University, Ubonratchathani, Thailand
}

\begin{abstract}
Safety of food in the fresh market has been a critical issue for many countries, including Thailand. In this study, data related to the criteria pertaining to food safety in selected fresh markets in Thailand are collected and analyzed using selective analytical methods to understand the perspectives of stakeholders in food safety system. In particular, our study considered 2 methodologies in the analysis1) Mixed Method Research based on questionnaires and interviews with an aim to analyze stakeholders' behaviours and 2) Analytic Hierarchy Process (AHP), one of the Multi Criteria Decision Making (MCDM) tools, with an aim to analyze criteria weights for food safety. Our case study was conducted at two fresh markets in Ubonratchathani province in Thailand: Municipal Market and Donklang Market, by collecting samples of vendors and consumers. It was found that vendors considered rental arrangement as the most important factor with weight 0.5489 (54.8 percent), whereas consumers concerned with the market building and related environment the most with criterion's weight 0.2480 ( 24.80 percent). This initial result can be used for further analysis of fresh market layout and design, subject to viewpoints of stakeholders.
\end{abstract}

\section{Introduction and Motivation}

Fresh markets have been widely distributed in almost all every community in Thailand, in which consumers and merchants can come to buy and sell various products, such as fresh vegetables, fresh fruits, meats, processed food as well as the ready-to-eat food. In particular, the fresh market is the place, where many people gather together, including the supplier of raw materials or farmers (i.e., supplier), vendors that sell products (i.e., distributor), the carrier of raw materials (i.e., transporter) as well as customers. Thus, various activities occur within the fresh market, which can be viewed as a kind of supply chain and value chain [1]. In fact, area and layout of the fresh market is an important element that is related to the food chain as well.

According to the national food safety policy analysis for Asian countries [2], food contaminated with chemicals, antibiotics, and pathogenic microorganisms, are the cause of deaths for more than 3 million people worldwide per year. In addition, food poisoning of approximately 1.5 million people worldwide per year is an evident of increasing health problem in the Asian population living in the city. Furthermore, the International Food Standards Commission (CODEX Alimentarius Commission) has prepared a draft manual 'principles and guidelines for national food control system' in early 2013 and proposed to the member countries for developing their national food control system for the management and development of food safety in the country [2].

Therefore, analyzing food safety in the fresh market is an important issue that should be managed for the fresh market area. Food sanitation, food safety, and consumer protection are also essential as well [3]. Since 2002, the Thailand government has announced the food safety policy, which emphasizes as aspect of food nutrition. That is, the sources of food production need to be safe and should not contain contaminants that can be harmful to health, which may be caused by the dirty market area, non-standard transportation methods, as well as adding food additives for commercial purposes. Unless the above factors for market contamination can be managed, consumers may have a greater risk of getting sick. [4]

\subsection{Research in Food Safety in Thailand}

Recently, many researchers have studied the food safety in the market in various areas [5-7]. For example, Chomnart and colleagues [5] have studied the development of community to manage food safety in villages in order to enhance a capability of food-safe communities. By using participatory research, the authors started the development with the discussion forum based on the situation of problems in pesticide residues in fresh food in the community and assessing the health effects caused by unsafe food consumption. According to the authors, providing proper and enough information and knowledge as well as practicing experiments related to testing toxic residues in food can help to raise awareness and promote the use of health guidelines for communities. In addition, the authors recommended that, consistent with many studies, the communities can learn from problems and proper practices can lead to self-solution and sustainable development.

\footnotetext{
*orresponding author: kasinphd@gmail.com
} 
Weerachai Boriboon [6] also studied the factors related to effectiveness of safe food operations in Singburi province in Thailand. The authors focused on the effectiveness from the level of public opinion on safe food operations and food hygiene. By observing operational roles of the food safety projects at the provincial health office and the health status of consumers in Singburi province in Thailand, the authors found that the effectiveness of safe food operations are at a high level. In addition, Pornwisa Prasertsaeng [7] studied the behavior of consumers in buying safe food in Chiangmai province, Thailand. The authors focused on factors that affect buying decisions based on the satisfaction score in purchasing safe food. The sample of 400 consumers are analyzed using descriptive statistics, the rating scale according to the Likert scale, and the Chi-square test. The authors found that many consumers are aware of 'Chiang Mai Food Safety Policy'. The behaviours of customers are to use safe food for cooking 3-4 times a week, spending on buying each time at 101 $200 \mathrm{baht}$, and there is a frequency of buying food more than 4 times a month. Moreover, the satisfaction score of the sample group of customers is found to be satisfied. Regardless of recent developments for research related to food safety in Thailand, these studies typically only use survey for their analysis of food safety only.

\section{Methodology}

\subsection{Case Study}

Research procedure in this work starts from analyzing the current problems of two fresh markets of the case study by interviewing the owner and the governmental officer responsible for the two respective fresh markets. In particular, two fresh markets for the case study are 1) the representative of the public fresh market (i.e., Ubonratchathani municipal market: UB market) and 2) the representative of the private fresh market (i.e., Donklang market: DK market) in Ubonratchathani province in Thailand. These two fresh markets are chosen under an agreement with the funding corporation. In addition, whereas operation time of UB market has been so far 59 years being the oldest fresh market in the province, DK market has operated for only about 15 years. Thus, they are interestingly good candidates for the representative fresh markets in this study, given different managerial policy and operation time. The general problems found are related to zoning and layout management as well as hygienic food.

Then, we use two particular tools for an analysis 1) Mixed Method Research, which is an analytical method suitable for a combination of quantitative and qualitative data. In particular, questionnaires, individual interviews, and group interviews are used to understand problem situations; 2) Analytic Hierarchy Process (AHP) is used as a representative of Multi-Criteria Decision Making (MCDM) tools, in which hierarchical analysis of AHP process can be used to analyze criteria weight important for the food safety market.

\subsection{Mixed Method Research}

We next discuss the mixed method research used in this study to analyze both quantitative and qualitative aspects of the samples. We initially collect data using questionnaire/ survey and an individual short interview for each sample, in which the questions are divided into 3 parts 1) General information, 2) Satisfaction score for factors related to the food safety and the fresh market, and 3) Open-ended questions related to suggestions for improving the market. With regard to the satisfaction score, we use Linkert scale from 1 (the most dissatisfied) to 5 (the most satisfied). These questions are intended to explore the behavior of consumers and vendors involving in the food safety and the fresh market. The collected samples for consumers and vendors of both markets are aiming at least 450 and 100 , respectively.

In particular, both quantitative data and qualitative data are simultaneously analyzed in this study. In the former, we analyze quantitative data using descriptive statistics, frequency, and percentage. Then, qualitative data are analyzed using content analysis for open-ended questions of the questionnaire. Then, information from open-ended questions are further categorized to come up with factors important for a success of food safety in the fresh market, which are to be further analyzed using AHP method.

\subsection{Analytic Hierarchy Process (AHP)}

The Analytic Hierarchy Process (AHP) was initially developed by Thomas L. Saaty in 1970 [9] as a tool for analyzing complex decisions. AHP is considered one of the popular MCDM methods that analyzes problems with qualitative data. In particular, AHP uses the principle of comparing each factor in pairs called pairwise comparison, which compares how one factor is more important than the other factor. The comparison scale illustrating the level of importance commonly used in AHP is from 1 to 9 [8]. Many researchers have used AHP technique as a decision tool to measure factors/criteria weight, which affects the decision [9-13]. However, studies that use AHP for food safety in fresh market have not been reported in the literature.

AHP, in particular, uses analytical principles based on the psychological principle and the use of mathematical models together in making pairwise comparison. The hierarchical structure of AHP typically starts from 1) the top layer as the target (i.e., Goal) of the problem, 2) the next layer is the chosen primary factor (i.e., Criteria) or the sub-factor (i.e., Sub-criteria), and 3) the final layer is possible choices or solutions of the problems (i.e., Alternatives). Fig. 1 illustrates the general structure of AHP.

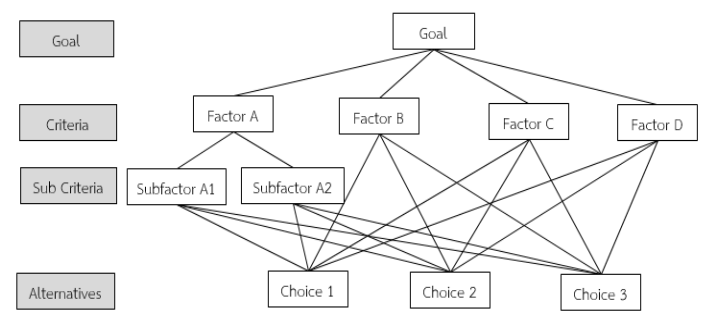

Fig. 1. Hierarchical structure of AHP 
We next discuss mathematical notations and computations for AHP. Initially, the number of times needed for pairwise comparisons is shown in Equation (1), where $\mathrm{N}$ is the size of the matrix or the number of factors of interest. The final results are weight values or relative weights associated with factors and/or alternatives. In this study, the analysis of factors related to food safety in the fresh markets is done using AHP method. We also plan to conduct the focus group using at least 7 representatives of consumers and at least 7 vendors from both markets to synthesize the weight data to understand the competent factors/criteria for the success of food safety in the fresh market.

The AHP methodology can be divided into the following main steps.

Step 1: Create a matrix table for pairwise comparison of factors and for options that are compared to each other as shown in Equation (2), where scales 1-9 are commonly used to be compared in pairs.

$$
\begin{gathered}
n(n-1) / 2 \\
A=\left[\begin{array}{ccccc}
1 & a_{12} & \ldots & a_{1 n} \\
a_{21} & 1 & \ldots & a_{2 n} \\
\ldots & a_{j i}=1 / a_{i j} & 1 & \ldots \\
a_{n 1} & \ldots & \ldots & 1
\end{array}\right]
\end{gathered}
$$

where $a_{i j}$ is the comparison of factors $i$ and $j$.

Step 2: Create a normalized matrix by dividing each value from the first step with the sum of each column of the matrix.

Step 3: Compute the priority vector or Eigen vector using weighted values for factors and for various alternatives (if any) as shown in Equation (3)

Step 4: Calculate the maximum Eigen value from the Eigen vector obtained from Step 3 called $\lambda_{\max }$

$$
A \cdot p=\lambda_{\max } \cdot p
$$

where $p$ is the local priority vector.

Step 5: Calculate the Consistency Index (CI) as shown in the equation (4)

$$
C I=\frac{\lambda_{\text {max }}-n}{n-1}
$$

Step 6: Select the appropriate value from the Random Consistency Index table (RI) by comparing with the size of the matrix (n) as shown in Table 1.

Table 1. The RI values for the AHP method.

\begin{tabular}{|l|c|c|c|c|c|}
\hline \multicolumn{1}{|c|}{$\boldsymbol{n}$} & $\mathbf{1}$ & $\mathbf{2}$ & $\mathbf{3}$ & $\mathbf{4}$ & $\mathbf{5}$ \\
\hline $\mathrm{RI}$ & 0 & 0 & 0.58 & 0.90 & 1.12 \\
\hline$n$ & 6 & 7 & 8 & 9 & 10 \\
\hline $\mathrm{RI}$ & 1.24 & 1.32 & 1.41 & 1.45 & 1.49 \\
\hline
\end{tabular}

Step 7: Evaluate the Consistency Ratio (CR) of the matrix using Equation (5).

$$
C R=\frac{C I}{R I}
$$

Step 8: Evaluate the ranking of each alternative (if any) according to Equation (6), where $l_{i j}$ is the local score of each choice. $i$ compared to $j ; w_{j}$ is the weighted value of factor $j$; and $g_{i}$ is the global score of any alternative $i$ of interest.

$$
g_{i}=\sum_{j} w_{j} l_{i j}
$$

We note that since our study only consider the weight of criteria deemed essential for the success of food safety in fresh market, we follow the computation of AHP using Equations (1)-(5), without Equation (6) in the analysis.

\section{Results and Discussion}

\subsection{Vendors and Customers Profiles analyzed using Mixed Method Research}

The results from analyzing questionnaires collected from two fresh markets show that most of the vendors are women. The average age of vendors at UB market is around 60 years old, whereas vendors at DK market are found to be younger in the range of 31-40 years old. The education levels of vendors in both markets are below the bachelor degree level. Regarding sales experience, the majority of vendors in UB market have more experience than DK market. In particular, the experience of vendors in UB market is more than 10 years, while the vendors at DK market is around 1-3 years. In addition, monthly sales volume shows that vendors at DK market have better sales volume.

We next discuss general data analyzed from customers. The majority of customers come to the market every day. The majority of gender of these consumers are female. The customers' age found at UB market is over 61 years old, whereas at DK market is in the range of 20-30 years old. The educational level of customers at both markets is below a bachelor degree. The monthly income is found to be less than 10,000 baht. The average spending per visit is around 100-200 baht. The duration of visiting each market is approximately 30-60 minutes. In addition, these customers come to the market by motorcycle. With regard to the occupation of consumers, customers of UB market own a private business and mostly work at home. On the other hand, customers of DK market are students. Furthermore, the types of goods that most people purchase from UB market are found to be vegetables and fruits, whereas customers at DK market buy vegetables and instant food. General data analyzed from vendors and consumers of both fresh markets are shown in Fig. 2. Clearly, the behavior of consumers with respect to the food selection is different. Thus, this information can be further used to plan for proper zone arrangement as well as market layout improvement that suits well vendors and customers' preferences, which is our on-going work 


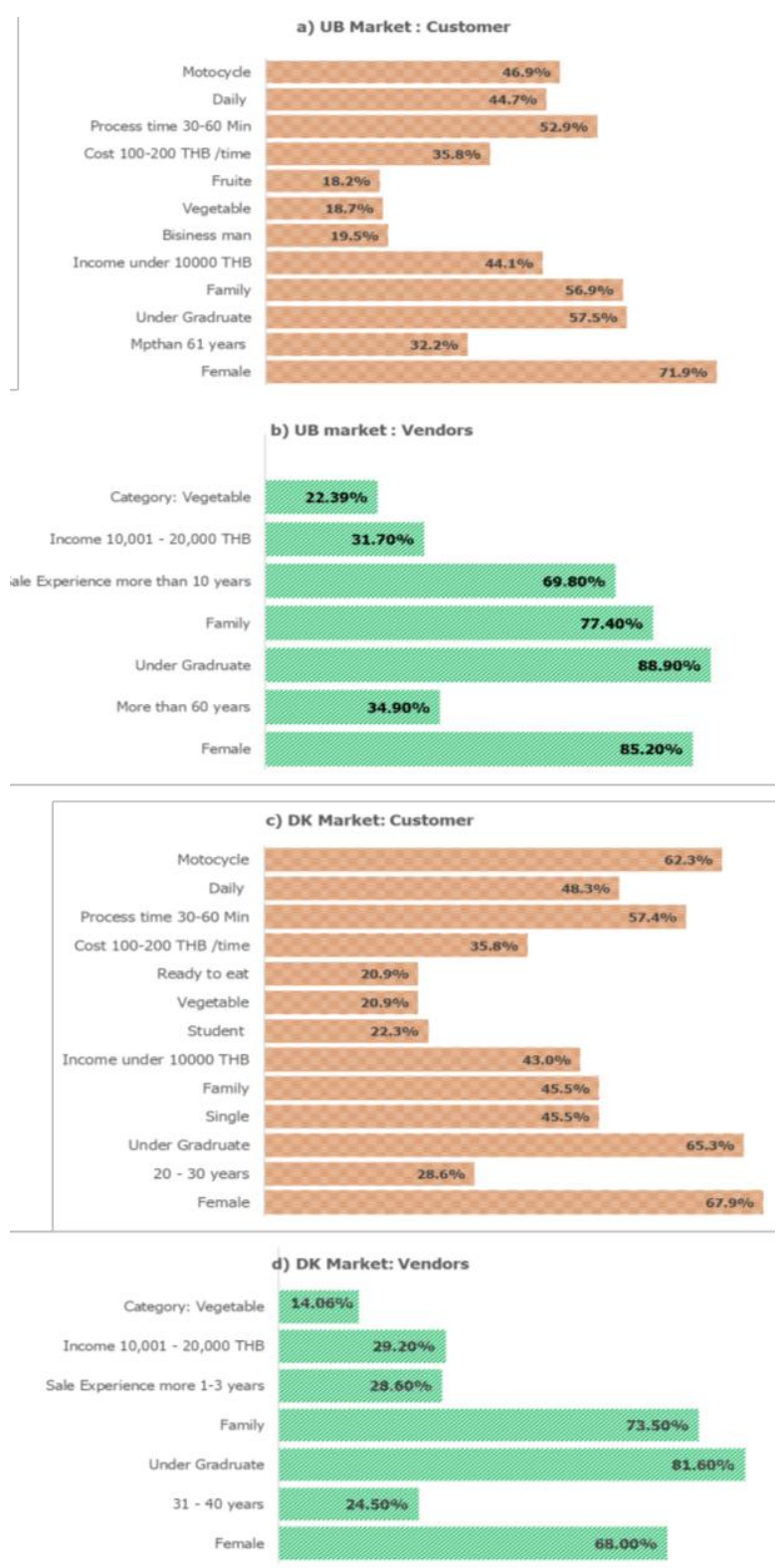

Fig. 2. General behavior of vendors and customers

Next, we synthesis satisfaction scores from various factors related to vendors and customers visiting both fresh markets from score 1 (the most dissatisfied) -5 (the most satisfied). Factors concerning vendors are analyzed in 3 aspects, which are 1) market building and environment, 2) rental prices and value, and 3) food safety and consumer protection. We find that the general satisfaction score of both markets for vendors are at a high level of satisfaction as shown in Table 2. Food safety and consumer satisfaction is found to be the factor that many vendors are satisfied, whereas the opinions for building and rental prices are varied.

In addition, satisfaction data for factors related to consumers are evaluated in 6 aspects, which are 1) product, 2) price, 3) building, 4) marketing promotion, 5) food safety and consumer protection, and 6) attitudes towards food safety. The results show that customers of both UB and DK markets have a high level of satisfaction as shown in Table 3. In particular, customers of both markets are satisfied with food safety and customer protection the most. On the other hand, promotion-related factor is found to be the least satisfied for customers of both markets.

Table 2. Satisfaction scores with respect to vendors of both fresh markets (Average and standard deviation)

\begin{tabular}{lcc}
\hline \multicolumn{1}{c}{ Factors } & \multicolumn{2}{c}{ Average Satisfaction } \\
\cline { 2 - 3 } & Score \\
\cline { 2 - 3 } & UB & DK \\
& $3.92 \pm 0.24$ & $3.85 \pm 0.24$ \\
\hline 1. Building & $3.39 \pm 0.45$ & $3.46 \pm 0.28$ \\
2. Rental price and value & $4.27 \pm 0.21$ & $4.04 \pm 0.20$ \\
3. Food safety and & & \\
consumer protection & & \\
\hline
\end{tabular}

Table 3. Satisfaction scores with respect to customers of both fresh markets (Average and standard deviation)

\begin{tabular}{|l|c|c|}
\hline \multirow{2}{*}{\multicolumn{1}{|c|}{ Factors }} & \multicolumn{2}{c|}{ Average Score } \\
\cline { 2 - 3 } & $\begin{array}{c}\text { UB } \\
\text { Market }\end{array}$ & $\begin{array}{c}\text { DK } \\
\text { Market }\end{array}$ \\
\hline 1.Product & $3.92 \pm 0.24$ & $3.85 \pm 0.24$ \\
\hline 2.Price & $3.39 \pm 0.45$ & $3.46 \pm 0.28$ \\
\hline 3.Building & $3.82 \pm 0.36$ & $3.69 \pm 0.24$ \\
\hline 4.promotion & $3.36 \pm 0.40$ & $3.41 \pm 0.24$ \\
\hline $\begin{array}{l}\text { 5.Food safety and consumer } \\
\text { protection }\end{array}$ & $4.41 \pm 0.04$ & $4.18 \pm 0.04$ \\
\hline 6.Attitudes of food safety & $4.27 \pm 0.21$ & $4.04 \pm 0.20$ \\
\hline
\end{tabular}

\subsection{Criteria Analysis using AHP}

We next discuss the synthesis of criteria/factors related to food safety of fresh markets by using the AHP method for vendors and customers. These factors are obtained from the content analysis of open-ended questions analyzed earlier in the previous section to come up with a list of factors deemed important for both vendors and customers of both fresh markets. Fig. 3 presents the AHP's hierarchical structure of factors for vendors, which consists of 3 main factors: 1) Building, 2) Rental and value, and 3) Food safety. In addition, factors related to 'building' and 'food safety' contain a number of sub factors. Then, based on the AHP analysis through a series of focus groups for vendors at UB market and DK market, the relative weights associated with each criterion is synthesized using group decision making as shown in Table 4. The consistency analysis performed for vendors of both markets reveals that decision makers have been acceptably consistent within 10\%. The analyzed results are found to be similar between the two fresh markets with more or less weights. That is, factor related to 'rental price and value' is ranked first, followed with 'food-safety' factor and 'building' factor, respectively. The overall criteria weights across two fresh markets are in particular $54.89 \%$ or $0.54,27.98 \%$ or 0.28 , and $17.13 \%$ or 0.17 , respectively. Fig. 4 summarizes associated factors' weight with respect to food safety of fresh market that are from vendors' perspectives. For example, when we look at the second ranked criteria of 'food safety', the ranking of sub-criteria and associated weights are found to be 'cleaning and pest control' with weight 0.44 , 'restroom cleanliness' 
with weight 0.31 , and 'hygiene of vendors' with weight 0.25 , respectively. In addition, when we look at the third ranked criteria of 'building', associated sub-criteria are found to be 'building condition, restroom, and parking' with weight 0.39 , 'zone management' with weight 0.36 , and 'shop category, signboard, and signs' with weight 0.25 , respectively. Understanding and emphasizing these main criteria as well as sub-criteria considered important for vendors can help to enhance the success of management for food safety in fresh markets.

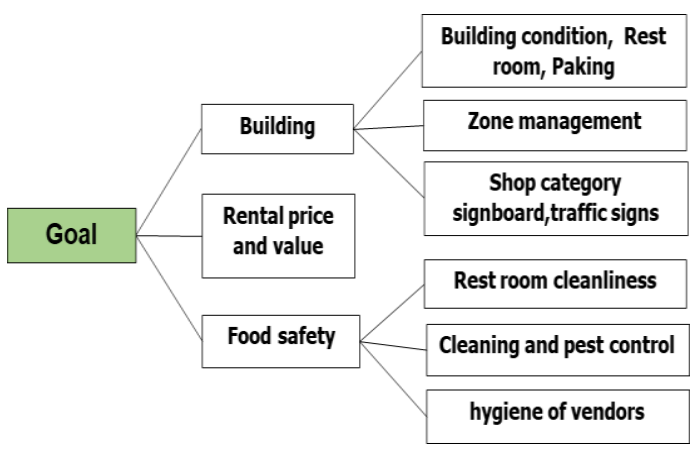

Fig. 3. AHP hierarchical structure for vendors

Table 4. Factors and weights of AHP for vendors

\begin{tabular}{|l|l|c|c|c|c|}
\hline \multicolumn{2}{|c|}{ Factors } & $\begin{array}{c}\text { UB } \\
\text { Market } \\
\text { \% }\end{array}$ & $\begin{array}{c}\text { DK } \\
\text { Market } \\
\text { \% }\end{array}$ & $\begin{array}{c}\text { Overall } \\
\text { \% }\end{array}$ & Rank \\
\hline 1 & Building & 17.75 & 16.51 & 17.13 & 3 \\
\hline 1.1 & $\begin{array}{l}\text { Building } \\
\text { condition, Rest } \\
\text { room, Packing }\end{array}$ & 42.48 & 35.15 & 38.81 & \\
\hline 1.2 & $\begin{array}{l}\text { Zone } \\
\text { management }\end{array}$ & 30.00 & 42.94 & 36.47 & \\
\hline 1.3 & $\begin{array}{l}\text { Shop category } \\
\text { signboard, } \\
\text { traffic signs }\end{array}$ & 27.52 & 21.91 & 24.71 & \\
\hline 2 & $\begin{array}{l}\text { Rental price and } \\
\text { value }\end{array}$ & 58.56 & 51.23 & 54.89 & 1 \\
\hline 3 & Food safety & 23.68 & 32.27 & 27.98 & 2 \\
\hline 3.1 & $\begin{array}{l}\text { Rest room } \\
\text { cleanliness }\end{array}$ & 25.83 & 36.57 & 31.20 & \\
\hline 3.2 & $\begin{array}{l}\text { Cleaning and } \\
\text { pest control }\end{array}$ & 56.67 & 31.35 & 44.01 & \\
\hline 3.3 & $\begin{array}{l}\text { hygiene of } \\
\text { vendors }\end{array}$ & 17.50 & 32.08 & 24.79 & \\
\hline & Consistency & 5.90 & 7.78 & 6.84 & \\
\hline
\end{tabular}

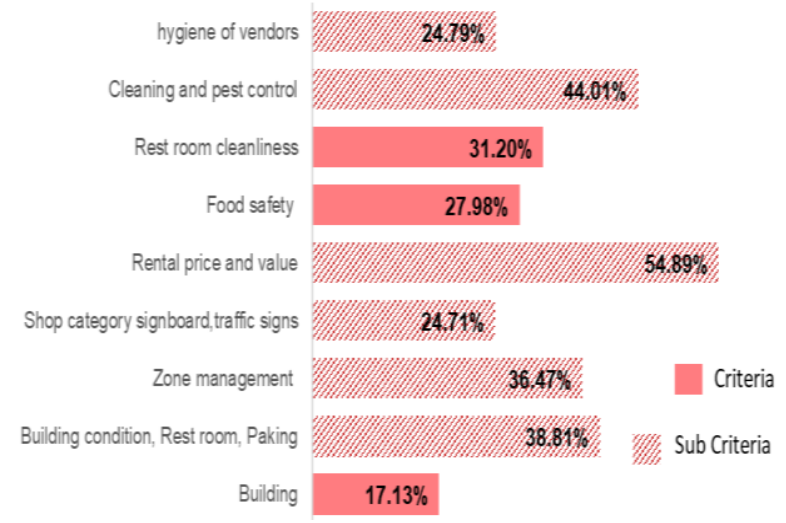

Fig. 4. AHP criteria' weights for vendors
Additionally, AHP-based factors/criteria analysis is performed for customers. The AHP's hierarchical structure is shown in Fig. 5 with five main factors: 1) 'Food safety and consumer protection', 2) 'Promotion', 3) 'Buildings', 4) 'Prices', and 5) 'Products'. In addition, four out of these five factors contain a list of associated sub-factors. Table 5 shows the analyzed factors and their weights of the factors. The consistency analysis performed for customers of both markets reveals that decision makers have been acceptably consistent within $10 \%$. With regard to the customers at UB market, the ranking of factors are 'product', 'price', 'building', 'promotion', and 'food safety and consumer protection', with associated weights of $29.7 \%$ or $0.29,24.3 \%$ or $0.24,22.9 \%$ or $0.23,15.8 \%$ or 0.16 , and $7.3 \%$ or 0.07 , respectively.

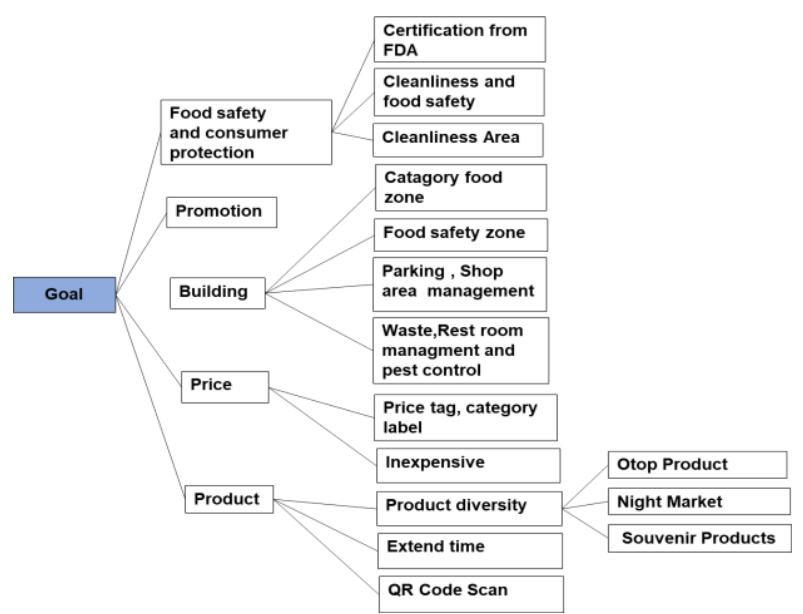

Fig. 5. AHP hierarchical structure for consumers

Table 5. Factors and weights of AHP for consumers

\begin{tabular}{|l|l|c|c|c|c|}
\hline \multicolumn{2}{|l|}{ Factor } & $\begin{array}{c}\text { UB } \\
\text { Market } \\
\text { \% }\end{array}$ & $\begin{array}{c}\text { DK } \\
\text { Market } \\
\text { \% }\end{array}$ & $\begin{array}{c}\text { Over } \\
\text { all } \\
\text { \% }\end{array}$ & Rank \\
\hline $\mathbf{1}$ & $\begin{array}{l}\text { Food safety and } \\
\text { consumer } \\
\text { protection }\end{array}$ & 7.30 & 33.20 & 18.40 & 4 \\
\hline 1.1 & $\begin{array}{l}\text { Certification from } \\
\text { FDA }\end{array}$ & 23.60 & 38.70 & 30.10 & \\
\hline 1.2 & $\begin{array}{l}\text { Cleanliness and } \\
\text { food safety }\end{array}$ & 48.30 & 32.40 & 41.40 & \\
\hline 1.3 & Cleanliness Area & 28.20 & 28.90 & 28.50 & \\
\hline $\mathbf{2}$ & Promotion & 15.80 & 6.60 & 11.80 & 5 \\
\hline $\mathbf{3}$ & Building & 22.90 & 27.30 & 24.80 & 1 \\
\hline 3.1 & Category food zone & 9.50 & 26.10 & 16.60 & \\
\hline 3.2 & Food safety zone & 33.10 & 9.10 & 22.80 & \\
\hline 3.3 & $\begin{array}{l}\text { Parking, Shop area } \\
\text { management }\end{array}$ & 15.10 & 23.30 & 18.60 & \\
\hline 3.4 & $\begin{array}{l}\text { Waste, Rest room } \\
\text { management and } \\
\text { pest control }\end{array}$ & 42.30 & 41.50 & 42.00 & \\
\hline $\mathbf{4}$ & Price & 24.30 & 15.50 & 20.50 & 3 \\
\hline 4.1 & $\begin{array}{l}\text { Price tag, category } \\
\text { label }\end{array}$ & 89.10 & 63.80 & 78.30 & \\
\hline 4.2 & Inexpensive & 10.90 & 36.20 & 21.70 & \\
\hline $\mathbf{5}$ & Product & 29.70 & 17.40 & 24.40 & 2 \\
\hline 5.1 & Product diversity & 28.90 & 67.60 & 45.50 & \\
\hline 5.1 .1 & OTOP Product & 11.20 & 32.30 & 20.20 & \\
\hline 5.1 .2 & Night Market & 73.30 & 58.40 & 66.90 & \\
\hline 5.1 .3 & Souvenir Products & 15.50 & 9.30 & 12.90 & \\
\hline 5.2 & Extend time & 39.20 & 18.50 & 30.30 & \\
\hline 5.3 & QR Code Scan & 31.90 & 13.90 & 24.20 & \\
\hline & Consistency & 6.11 & 6.11 & 6.11 & \\
\hline & & & & & \\
\hline
\end{tabular}


On the other hand, customers at DK market places an importance on 'food safety and consumer protection', followed with 'building', 'product', 'price', and 'promotion' with weights of $0.33,0.27,0.17,0.15$, and 0.06 , respectively. Overall, the results of the weight values across both markets show that consumers pay more attention to 'building' the most followed with 'product', 'price', 'food safety', and 'promotion' with relative weights of $0.25,0.24,0.21,0.18$, and 0.12 , respectively.

Besides, Fig. 6 summarizes associated factors' weights with respect to food safety of fresh market that are from the perspectives of customers across the two fresh markets. For example, when we look at the highest ranked criterion, which is 'building', associated sub-criteria are ranked with 'Waste, Rest room management and pest control', 'Food safety zone', 'Parking', Shop area management', and 'Category of food zone', respectively. The 'product' criterion, in addition, contains three sub-criteria, in which one of them is associated with three more sub-criteria (i.e., sub of sub-criteria). Again, emphasizing these main criteria as well as associated sub-criteria deemed important for customers can help to enhance the success of management for food safety in fresh markets.

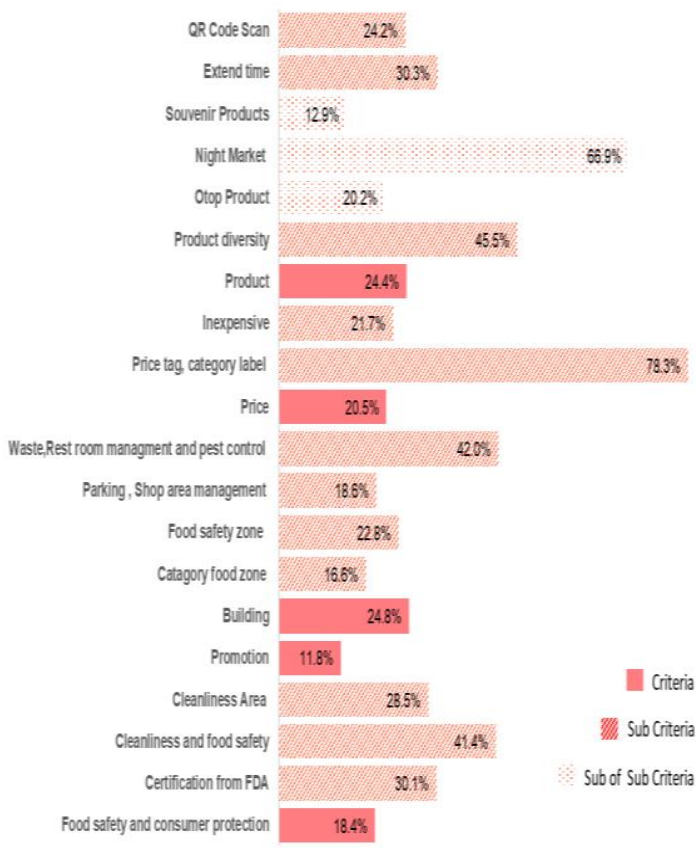

Fig. 6. AHP criteria' weights for consumer

Last but not least, when we look at an overall assessment of criteria emphasized by vendors and consumers based on the AHP approach, it is interesting found that whereas vendors view 'rental price and value' as the most important criterion, consumers view 'building' criterion and its associated environment around the building as the most concerned criterion. This insight is not surprising considering that vendors are understandably more interested in their incomes and costs, whereas consumers will be more serious and pay more attention to the place or the condition of the market building first whether they will be interested to visit.

\section{Conclusion and Future Research}

The preliminary analyses of quantitative data for stakeholders (i.e., vendors and consumers) perspectives of the two representative fresh markets revealed the overall behavior as well as satisfaction levels in food safety. Then, the analyses of qualitative data using openended questions and interview showed a list of essential factors/criteria deemed important for the success and improvement plan of the fresh markets. Then, the criteria analysis was conducted using Analytic Hierarchy Process (AHP) for vendors and consumers of both fresh markets using a series of focus groups. In particular, vendors and consumers have different perspectives with regard to their interest on successful criteria of the market concerning food safety. In particular, the consumers place the highest importance on 'building of the market' criterion, followed by 'product', 'price', 'food safety', and 'sales promotion' respectively. Thus, the key take away is that consumers value 'building' factor, which is related to food zone management of shop space, parking space, waste management, restroom cleanliness, and pest control. Thus, the success of food safety aspect for the fresh market needs to take these criteria into account.

Our on-going future research is to propose and design the zone and area of the fresh markets in order to increase the efficiency of the area by taking previously analyzed criteria into account. In addition, other tools, such as monte-carlo simulation could be integrated to further evaluate different zoning alternatives.

The first author acknowledges the Office of the Scientific Promotion Committee, Research and innovation center at Ubonratchathani University. The corresponding author acknowledges the funding from Thailand Science Research and Innovation (TSRI/TRF) and Ubonratchathani University under project 'Food Safety and Innovation' for grant RDG61A0030/004

\section{References}

1. W. Bunsri, W. Chantasorn, , KhonKaen. Graduate Research Conference, Khonkaen University), 16451651, (2013).

2. J. Witthayarungruengsri, J. Klinsoda, W. Tangkanakul, JFDA., 47-61, (2013)

3. Bureau of Food and Water Sanitation, Department of Health. (Buyable Fresh Market Guide. Bangkok: Agricultural Cooperative Assembly of Thailand, (2013))

4. S. Phupui, M. Intharakhaeng, JHSR., 10 (2), 50-60, (2016)

5. C. Potjanamat, S. Chayawat, S. Krankaew, N. Chanchaew, JNR., 39 (1), 35-45, (2012)

6. W. Boriboon, J Assoc Preventive Medicine Thailand, 5 (2), 162-172, (2015)

7. P. Prasertsang, Buying behavior of food crops for consumers' safety in Mueang District Chiangmai Province. Chiang Mai, (2012). 
8. M. Wanasanan, and S. Saisaengchan, National Sci Technol., 17 (4), 65-78. (2009)

9. S. Jaiyod, A. Theeranuphattana, J Bus Adm Res, 35 (134), 65-89, (2012)

10. M. Khangkun, A. Sopadaeng, J Oper Res Soc, 3 (2), $1-8,(2015)$
11. V. Elia, M.G. Gnoni, A. Lanzilotto, Expert Syst Appl, 63, 187-197, (2016)

12. A.D. Guritno, R. Fujianti, D. Kusumasari, JAS., 3, 51-55, (2015)

13. E. Gunes, H. Movassaghi, JAS.,5(1), 84-92, (2017) 